\title{
Arquitectura y sal. Historia y curiosidades Architecture and salt. History and curiosities
}

\author{
José Luis García Grinda, Universidad Politécnica de Madrid
}

DOI: $10.20868 /$ ciur.2020.128.4392

\section{DESCRIPTORES:}

Arquitectura de la sal/ Historia de los Paisajes Culturales de la sal/ Historia de las salinas españolas/ Salinas y alfolís

\section{KEY WORDS:}

Salt architecture/History of Salt Cultural Landscape/ History of Spanish salt pans/ Salt pans and storehouses

\section{RESUMEN:}

Acercamiento personal a la historia de la arquitectura de la sal, a través del estudio y documentación de ejemplos españoles. Empleamos el término arquitectura definido por William Morris (1881), en una concepción territorial incorporada en las contemporáneas definiciones patrimoniales: Paisaje Cultural (Carta de Cracovia, 2000), como el resultado y reflejo de una interacción prolongada a través de diferentes sociedades entre el hombre, la naturaleza y el medio ambiente físico.

Los primeros contactos con salinas mediterráneas, como las de Cabo de Gata, la masiva presencia de fábricas de salazón romanas, como la de Sexi con origen fenicio. Salinas de mar modernas que emplean la amplitud de la marea, como Las Puntas en la isla canaria de El Hierro. Las salinas de interior, con utilización desde el neolítico y de gran importancia desde época medieval, como Poza de la Sal, Imón o Belinchón, vinculadas a trabajos de Inventario del patrimonio arquitectónico y declaraciones de BIC de los años 70 y 80 y otras investigaciones del patrimonio rural español. Su relación con la ganadería y la Mesta, su transporte histórico apoyado en la Cabaña Real de Carreteros, para detenernos en ejemplos de alfolíes y almacenes, presentes en salinas y núcleos de población.

\section{ABSTRACT:}

Personal approach to the history of salt architecture, supported by studies and research of Spanish examples. We use the term of Architecture used by William Morris (1881), with a territorial concept incorporated in modern heritage definitions: Cultural Landscape (Krakow Charter of 2000)

First contacts with Mediterraneam salt pans, such as Cabo de Gata, the massive presence of Roman salting factories, such as Sexi with Phoenician origen. Modern sea salt pans that uses the breadth ot the tide, such as Las Puntas on the Canary island of El Hierro. Interior salt pans were used since the Neolithic and they had great importance since medieval times, such as Poza de la 
Sal, Imón or Belinchón. These salt pans are linked to inventory works of architectural heritage and BIC statements of the 70s and 80s and other research on Spanish rural heritage. Its relationship with livestock and the Mesta; its historical transport supported by the Cabaña Real de Carreteros. And finally stop at architecture of salt stores in salt pans and towns.

\footnotetext{
* José Luis García Grinda Arquitecto y Doctor ETSAM. Catedratico Universidad, Departamento de Composicón Arquitectónica. UPM. Email jl.ggrinda@upm.es

ORCID: http://orcid.org/0000-0001-86587-0871 (José Luis García Grinda)
}

\section{ARQUITECTURA DE LA SAL}

\subsection{Introducción}

Realizaremos a lo largo de estas líneas un acercamiento a la que venimos a llamar arquitectura de la sal en España, a través de la experiencia personal en su estudio y documentación que hemos venido realizando en distintos trabajos durante casi medio siglo. Ello puede confrontarse con la utilización del término Paisaje Cultural utilizado para denominar al Seminario Internacional dedicado a esta temática, donde se enmarcó una exposición con similar objetivo que el presente texto. Utilizamos para ello el término arquitectura que consagró William Morris en una conocida conferencia, impartida el 10 de marzo de 1881 en The London Institution, concepto que habitualmente utilizamos y explicamos a nuestros estudiantes en las aulas, donde aquella "abarca toda consideración del ambiente físico que rodea la vida humana" y es "el conjunto de modificaciones y alteraciones realizadas producidas en la superficie terrestre para satisfacer cualquier necesidad humana" (Morris, 1884). Es decir, una concepción amplia de carácter territorial que enlaza nítidamente con los conceptos contemporáneos de patrimonio, donde las estructuras territoriales y los paisajes como patrimonio cultural se conciben como el resultado y el reflejo de una interacción prolongada a través de diferentes sociedades entre el hombre, la naturaleza y el medio ambiente físico. Son el testimonio de la relación del desarrollo de comunidades, individuos y su medio ambiente (Carta de Cracovia, 2000) y por tanto donde se incorporan asentamientos, casas, edificaciones diversas comunitarias y auxiliares, caminerías e infraestructuras de comunicación, abastecimiento, riego y distintos tipos productivos...etc.

\subsection{Salinas de mar y factorías de salazón}

Los primeros contactos se realizan a principios de los años 70, en acercamientos a algunas salinas mediterráneas, donde se visitan y fotografían sus organizaciones como las salinas del Cabo de Gata, sitas en un borde del Golfo de Almería. En ellas destaca su poblado salinero organizado en bloques lineales de viviendas de una altura, actuando como hito su iglesia con su esbelto campanario, inaugurada en 1907 y restaurada recientemente, en una sencilla arquitectura encalada construida a caballo de los siglos XIX y XX. La actividad de los trabajadores de las salinas se complementaba con la pesca realizada en pequeñas embarcaciones, que eran varadas en la vecina playa con ayuda de tornos de madera asentados en la orilla. Estas salinas mediterráneas, cuyas organizaciones en grandes eras o saleros están adaptadas a zonas donde el 
litoral ofrece áreas planas y bajas conectadas con el mar, corresponden normalmente a etapas de construcción que podemos situar a partir del último tercio del siglo XVIII y especialmente avanzado el siglo XIX, una vez avanzado el control y defensa de nuestro litoral mediterráneo y en coincidencia con el impulso productivo que se producirá con el desestanco, a partir de la liberalización marcada por la Ley de Desentanco de la Sal de 1871, con la venta a particulares de las antiguos espacios salineros anteriormente controlados por el Estado.
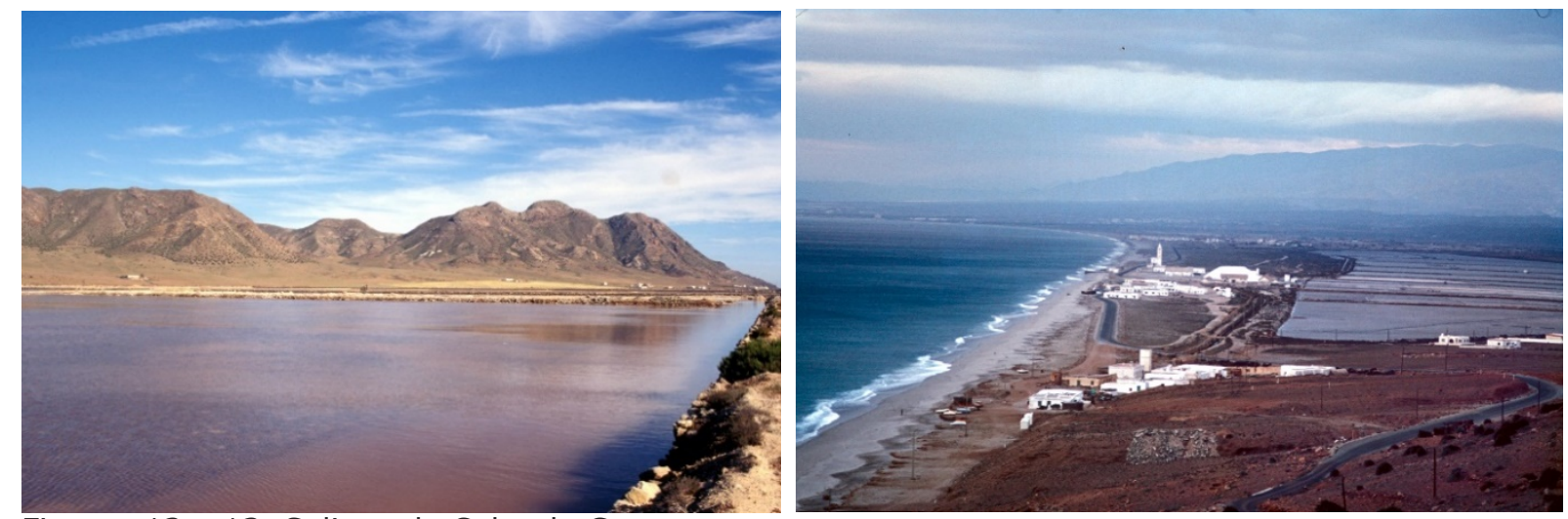

Figuras 12 y 13. Salinas de Cabo de Gata.

Fuente: Autoría José Luis García Grinda, años 70
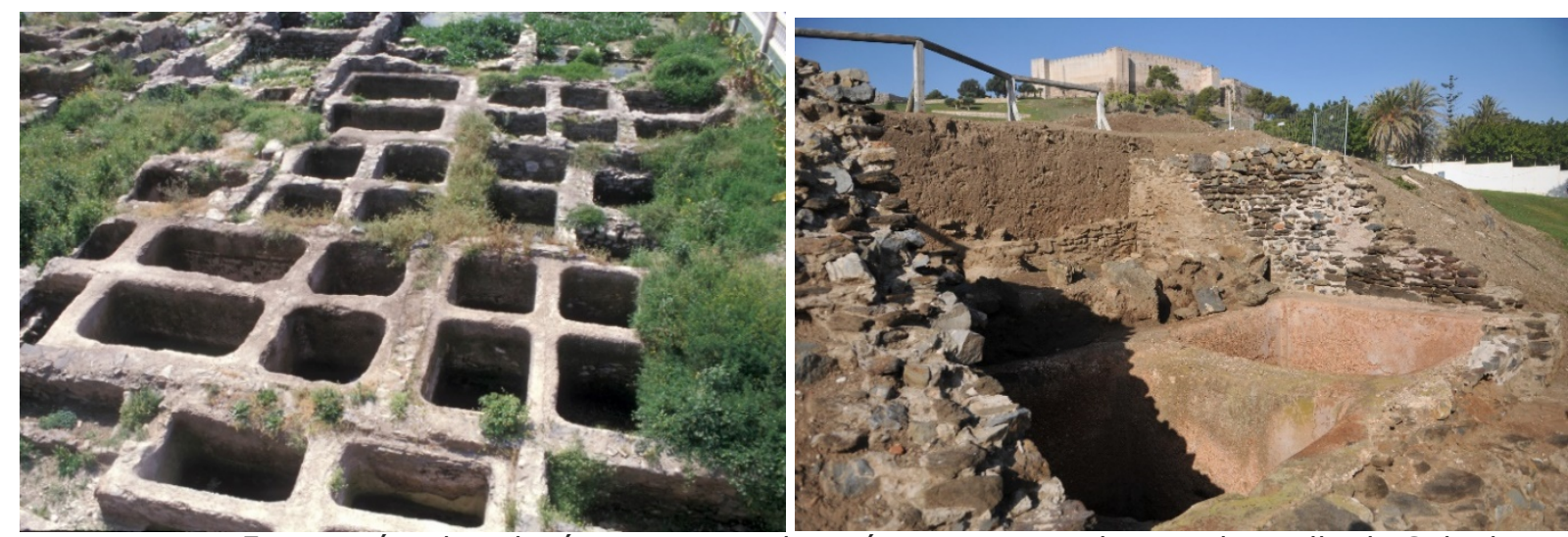

Figuras 14 y 15. Factorías de salazón romanas. Almunécar y Fuengirola con el castillo de Sohail. Fuente: Autoría José Luis García Grinda, años 70 y 2019

La actividad de salazones en la antigüedad nos ha dejado los restos de un buen número de fábricas o factorías a lo largo de las costas suratlánticas y mediterráneas, cuya presencia se densifica particularmente en los siglos I al II de nuestra era, desde el cabo de San Vicente al de la Nao. Estabrón nos da noticia de las fábricas de salazones en Menlaria, Gades, Baelo, Carteia, Malaka, Sexi y Carthago Nova (Estabrón, 7 a.C.), entre otras (Ponsich, 1988). Esta actividad fue extendida siglos antes en nuestra costa por la presencia fenicia, gozando de merecida fama las salazones hispánicas junto con el garum (Ponsich y Tarradell, 1967), salsa realizada con salmuera y restos de pescado de distinto tipo, donde destacará la producción de Gades, citada en el siglo $\mathrm{V}$ aC. por Eupolis, autor ático de comedias, por Antífanes hacia el año 390 a.C. y Nicóstratos hacia el 380 a.C. junto a las salazones de Bizancio (Tovar y Blázquez, 1975). 
Sin duda, una de las factorías romanas hispánicas exacavadas de mayor dimensión sea la de Almuñécar (Granada), antiguo Sexi, mas de medio centenar de pilas, aunque una parte de ella está oculta bajo el vecino parque arbolado. Asentada al lado meridional del promontorio donde se asentaba la antigua población, castillo y actual caso histórico de Almuñecar, mientras que otra se encontraba en el borde septentrional. Esta factoria llamada del Majuelo contaba con un muelle de atraque y un templo dedicado posiblemente a Minerva, en la parte más elevada. Se ha datado junto sus edificios administrativos en el siglo I de nuestra era, conservando su funcionamiento hasta el siglo IV, aunque se asientan sobre los restos de una factoria fenicia del siglo $\mathrm{V}$ a.C.. Las salazones de Sexi son citadas hacia el 300 a.C. por el autor cómico Dífilo de Sinope, señalando "que superan por su delicadeza y suavidad a las Amiclea" (García Bellido, 1953), confirmando la importancia de esta actividad en la península, particularmente en la antigua Turdetania romana, siendo una de sus principales fuentes de riqueza.

No desparecerán las factorías de salazón en nustro territorio costero con la caída del imperio romano de Occidente, a pesar de la crisis que afectó a nuestro territorio, manteniéndose esta actividad con una cierta presencia desde época tardoromana hasta época de dominación visigoda y bizantina, en los siglos VI y VII, como se deduce de algunas factorías de salazón excavadas, como la del Puerto de Mazarrón, hallada al hacer la cimentación de un edificio a finales de los años 70, estando fechada en los siglos IV-V de nuestra era y convertida en un espacio museístico (Iniesta y Martínez, 2005). En ella se organizan pilas de distinta profundidad y tamaño, destinadas tanto a la salazón como a la fabricación del garum e incluso de la púrpura, actividad que era frecuente en las factorías romanas, como se deduce del hallazgo de distintos tipos de ánforas halladas, como la denominada spateium caracterizada por su esbelted, destinada al transporte de la famosa salsa que era exportada a lo largo del mundo mediterráneo.

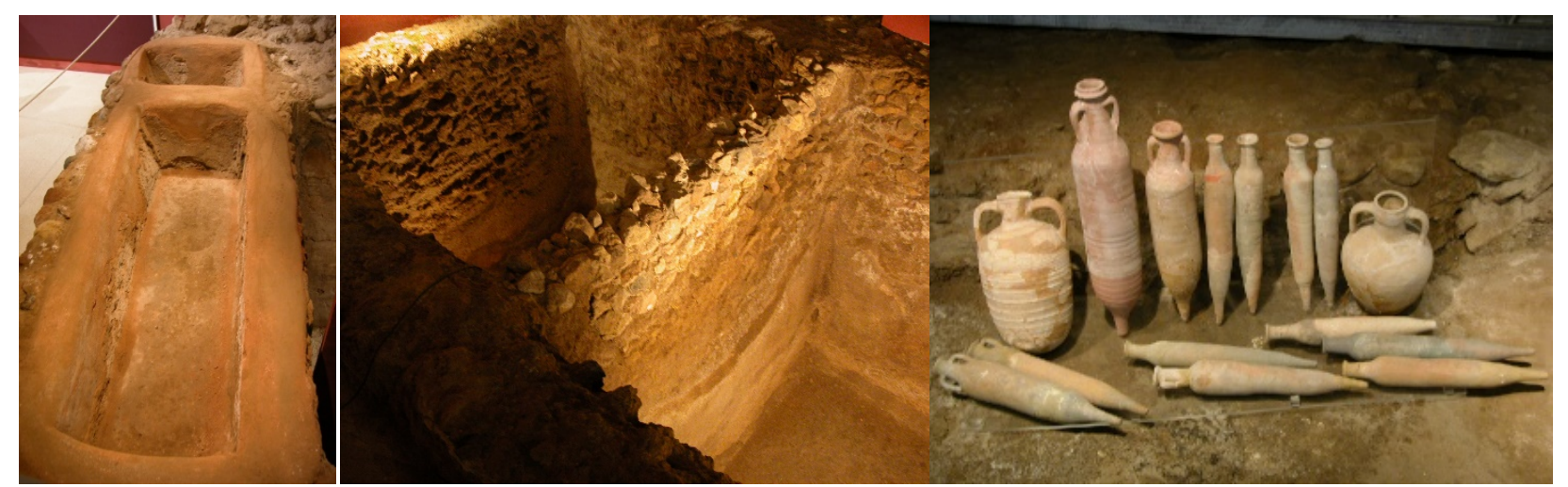

Figuras 16, 17 y 18. Factoría de salazón romana. Puerto de Mazarrón. Pilas de garum y salazón y ánforas.

Fuente: Autoría José Luis García Grinda, años 90

La explotación salinera debió ser importante para atender esta importante actividad pesquera en la Hispania romana, muy posiblemente explotándose los lugares donde hoy encontramos las salinas costeras modernas, particularmente las albuferas naturales. En nuestros viajes hemos podido detectar posibles pilas de salazón antiguas talladas en los sustratos rocosos de la costa mediterránea, 
particularmente constituidos de roca calcearenita, de gran facilidad en su tallado. En ella también se han documentado en algunos lugares estanques tallados como viveros de peces vinculados a explotaciones de villas romanas y salazones, como los llamados Baños de la Reina de Calpe y Jávea, o en la Albufereta de Alicante, conectados directamente con el mar, incluso pudiendo, como el primero, ser vecinos de actuales salinas. Un ejemplo de pequeñas piletas, cuya escasa profundidad y tamaño confirman su utilidad salinera, lo encontramos en Calblanque (Murcia). Estan talladas en el borde del mar, curiosamente pegadas al punto donde las actuales Salinas del Rasall elevaban el agua del mar con una noria, cuyos restos metálicos todavía se pueden visualizar en el lugar, conectada a un canal tallado en el estrato rocoso que la llevaba a las salinas actuales.
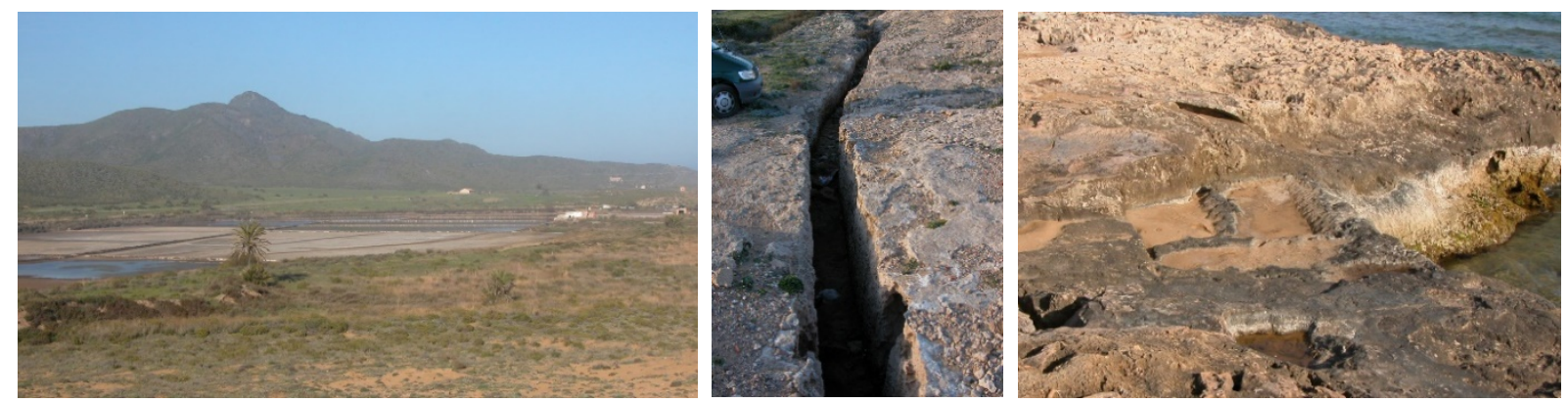

Figuras 19, 20 y 21. Salinas del Rasall. Calblanque (Murcia). Pilas antiguas, canal y salinas. Fuente: Autoría José Luis García Grinda, años 90

Un ejemplo de salinas costeras, que hemos podido reseñar en viajes de estudio y guarda relación con las anteriores eras primitivas, es el de Las Puntas en la isla canaria de El Hierro. Documentada en el siglo XVII, aprovecha el roquedo costero para regularizar y crear, en paralelo al mar, un basamento horizontal realizado en mampuesto de piedra volcánica. Sobre el se organizan las eras, con unos pequeños resaltos delimitadores de mampostería menuda, con dimensiones limitadas en una malla semiregular. Aunque esta posición más elevada a las cotas de mareas máximas no ha evitado que haya sufrido daños en algunos temporales, teniendo que reconstruir una parte del basamento. La salina utiliza la subida de la marea recogiendo el agua en el roquedo situado en un lateral que es conducida, por un canal tallado en la roca, a un primer depósito construido con muretes pétreos del que se eleva manualmente a otros tres depósitos escalonados. Del superior se distribuye a las eras, después de haberse calentado y evaporado parte del agua recogida. Junto a él se emplaza una edificación con cubierta vegetal que sirve de apoyo a dicha producción. Es una de las múltiples soluciones que las salinas costeras canarias emplean para poder tomar el agua marina del Atlántico, teniendo en cuenta las mareas y el perfil de la costa, recogidas en una espléndida ublicación (Marín y Luengo, 1994) . 

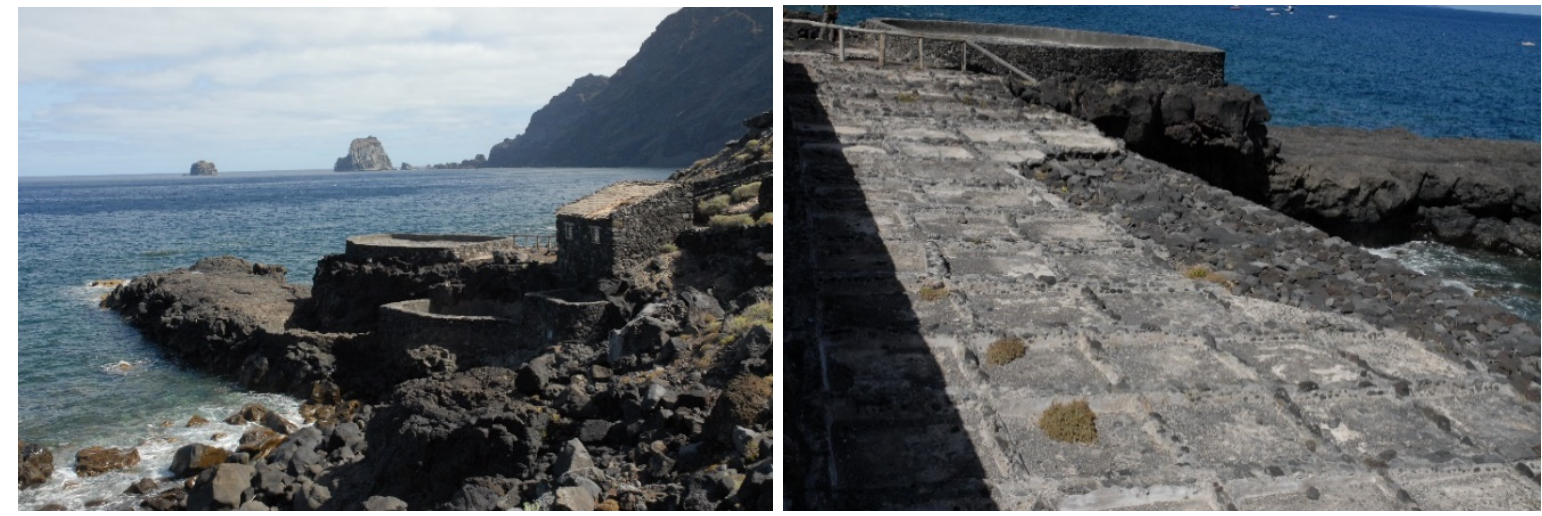

Figuras 22 y 23. Salinas de Las Puntas. El Hierro (Canarias). Organización general y eras salineras. Fuente: Autoría José Luis García Grinda, año 2008.

\subsection{Salinas de interior: Poza de la Sal, Imón, Olmeda y Belinchón}

Los trabajos de documentación de arquitectura que realizamos en los años 70, en el territorio de la Provincia de Burgos, nos permitieron ponernos en contacto con las salinas de interior, en particular las de Rosío, Herrera, todavía en funcionamiento en aquel tiempo, y Poza de la Sal. Estos trabajos arrancan con la Reseña de la Arquitectura de la Provincia de Burgos (1977-78), el primer trabajo de inventario arquitectónico apoyado en un sistemático trabajo de campo en nuestro país, además de la correspondiente explotación bibliográfica previa. Lo seguirá el Inventario del Patrimonio Arquitectónico (1979-80) de la misma provincia, ganado por concurso público convocado por el Ministerio de Cultura (García Grinda, 1982) donde se profundizará en la búsqueda y documentación de arquitecturas aisladas de acceso difícil. Todos estos trabajos tendrán reflejo en una exposición, que tendrá un recorrido itinerante, y su corresponiente publicación (García Grinda, 1983 y 1984) por encargo del COAM, en los años 80, donde se señala ya el interés específico de las salinas de Poza de la Sal. Todavía en estos años se conservaban en pie, pues habían dejado de explotarse en el año 1974, algunas de las chozas que servían, en su parte inferior, como almacenes locales de sal y, en su parte superior, como era para la producción final de la sal, construidas sobre soportes verticales de madera y cerramiento de mampostería pétrea o incluso con tablones horizales de madera, en soluciones parejas a las de Añana, aunque el ejemplo de arquitectura conservado es el edificio de administración de las salinas, destinado hoy a centro de interpretación, edificado en el siglo XVII en el borde del recinto medieval amurallado de Poza, en forma de casona pétrea blasonada.

El diapiro de Poza de la Sal, uno de los ejemplos más claros de este tipo de formación geológica, estudiado por el geológo alemán Hempel (1967), esta vinculado a importantes presencias de la Antigüedad, con el castro autrigón asentado en el cercano Cerro del Milagro, identificado con Salionca o Salionica, con presencias arqueológicas desde el neolítico hasta la edad del hierro, para extenderse en el siglo I a sus pies en un asentamiento de mayor dimensión, con el nombre de Flavio Augusta. Martínez de Santaolla, nos dá referencias, en sus excavaciones arqueológicas de los años 20, de una importante necrópolis organizada en calles paralelas, compuestas con tumbas coronadas con unas 
singulares urnas oikoformas (Abásolo, Albertos y Elorza, 1975), en un número de trescientas, hoy diseminadas por distintos museos nacionales y extranjeros. En el centro del diapiro emerge hasta los 1.000 de altitud un roquedo de ofita, piedra volcánica explotada desde tiempos antiguos e incluso empleada en la contrucción de pozos y chozas de las salinas, con la denominación de El Castellar, donde se hallaron restos de ocupación de la edad del hierro, cuyo castro tenía con toda seguridad una misión de control y vigilancia de la antigua explotación salinera. La ocupación y casi segura explotación salinera desde época neolítica se relaciona con las marcas de hogueras halladas en Añana, confirmando el método de evaporar calentando en ollas cerámicas el agua salada para la extracción de sal en dicha época neolítica.

El sistema básico de extracción de la sal de Poza, espléndidamente descrito y dibujado por Sáiz Alonso (Sáiz, 1989), es distinto al de otras salinas de interior españolas, donde se extrae del agua natural superficial, como Añana, o subterránea mediante pozos, como las de la comarca de Atienza. Se pone en conexión con otros sistemas antiguos de explotación minera, extendidos en época romana y conocidos como Ruina montium, ejemplificados en las minas de oro del NO hispánico, como Las Médulas o Montefurado. Aunque existen algunos espumeros menores en superficie, la extracción de la sal se realizaba haciendo pasar agua dulce sobre el estrato salino, situado a una profundidad de 8 a $30 \mathrm{~m}$., excavando unas galerías conectadas a pozos verticales, unos al inicio superior del diapiro, por donde se deja caer el agua dulce procedente de distintas fuentes y almacenadas en depósitos reguladores, y otros intermedios, a lo largo del desarrollo de las galerías, para permitir su limpieza y excavación. Y otros al final de ellas, donde se puede extraer la sal muera utilizando unos capachos de piel manejados con un torno. Estos pozos estaban protegidos por unas casetas construidas en fábricas de adobe o cerramientos de madera y cubierta vegetal. Este proceso de extracción de tipo minero producía continuos cambios del terreno y pequeños derrumbes al ir lavando el sustrato salino, necesitando construir nuevos pozos y galerías, documentando a mediados del XIX más de 30 pozos o cañas en funcionamiento.
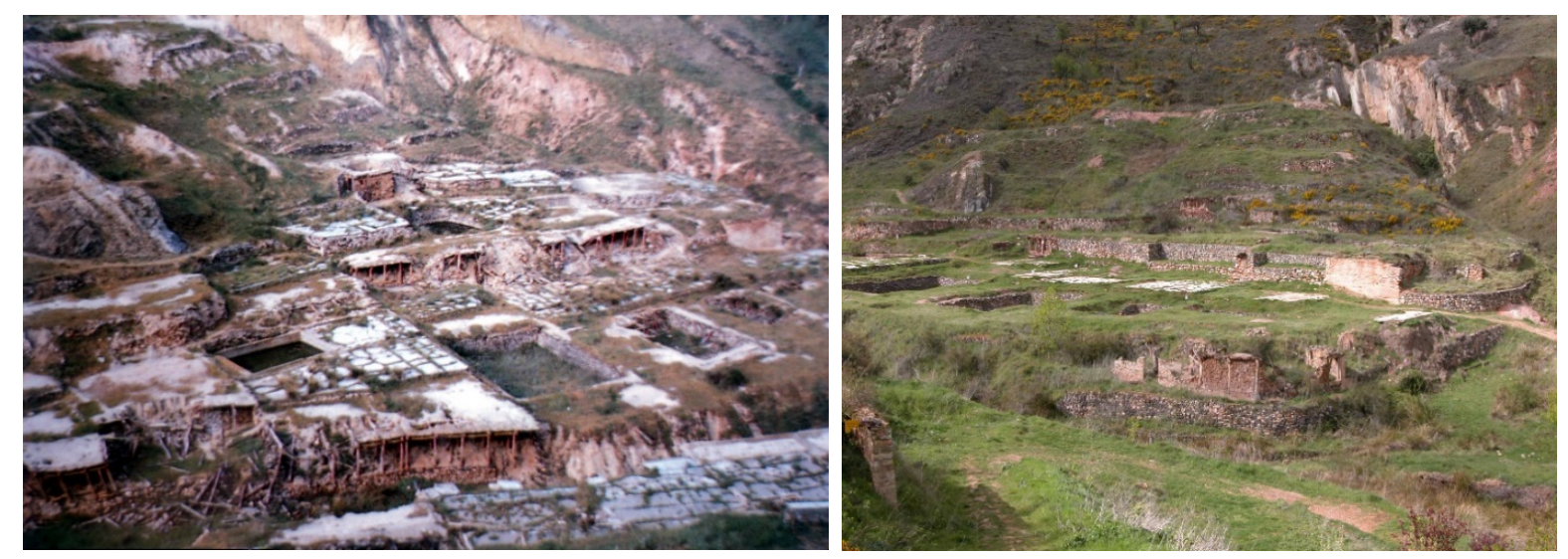

Figuras 24 y 25. Salinas de Poza de la Sal (Burgos). La misma zona a finales de los 70 y 90 , parcialmente reconstruida recientemente.

Fuente: Autoría José Luis García Grinda 

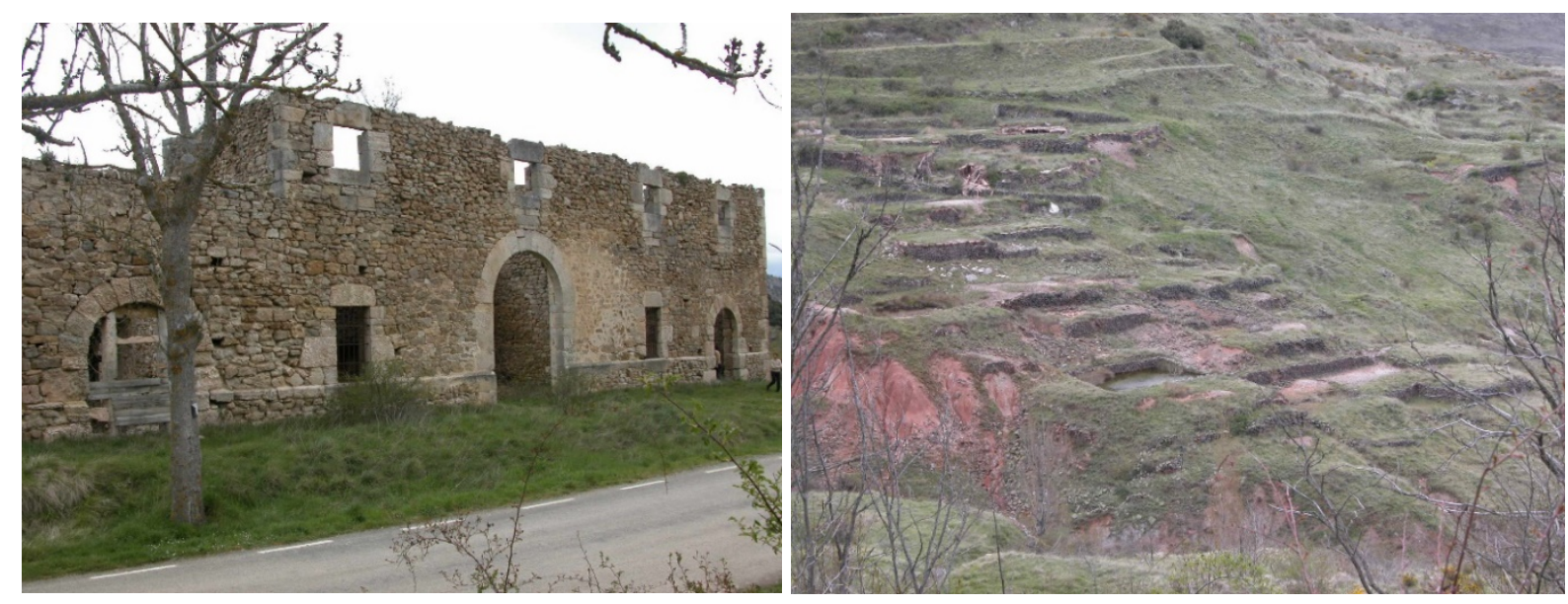

Figuras 26 y 27. Salinas de Poza de la Sal (Burgos). Marcas de eras-chozas en zona alta del diapiro y ruinas del almacén de Trascastro, años 90.

Fuente: Autoría José Luis García Grinda

Hoy en el conjunto del diapiro, rodeando El Castellar, se aprecian las marcas escalonadas de las chozas-eras, unas dos mil, con algunos restos de los muros de apoyo de las mismas, estando contruidos en fábrica de mampostería pétrea que actúan como muros de contención del terreno, al aterrazar la pendiente natural del mismo, habiendo desparecido casi en su totalidad las estructuras verticales que soportaban las eras salineras y el amacenamiento inferior, conformados por postes de madera y con rellenos parciales de mampostería y adobes. Recientemente se han reconstruido en la zona más cercana al núcleo un pequeño núcleo de chozas-eras como elemento demostrativo de su organización original. Todavía destacan en el conjunto los muros exteriores y rampas de dos de los grandes almacenes construidos a finales del siglo XVIII, aunque hay perdido sus cubiertas: Trascastro y La Magdalena, habiendo desaparecido otro en Las Almendreras a mediados del XIX, además de los muros del edificio del depósito o alfolí emplazado en el borde de la villa, cercano al edificio de administración citado, estando en claro peligro de derrumbe como ha ocurrido con los muros de la ermita de la Magadalena que se emplaza cerca del almacén del mismo nombre.

En 1983 elaboramos la documentación para la declaración de Monumento Nacional de las salinas de Imón (Guadalajara), incoadas en 1979, por encargo del Ministerio de Cultura dentro del Programa de Declaraciones de Monumentos y Conjuntos que siguió a la redacción del citado Inventario del Patrimonio Arquitectónico. Ello nos permitió conocer y estudiar (García Grinda, 1983) el conjunto salinar interior peninsular al que pertenece, vinculado al río Salado en una llanura al pie de las montañas continuadoras de las Sierras de Paredes y Somosierra. En aquel momento todavía funcionaban las de Imón y La Olmeda de Jadraque, también conocida como salinas de Bonilla, gestionadas ambas por la compañía Salinas de Imón y Olmeda que tenía su sede en Sigüenza, creada en 1873 fruto de la privatización consiguiente al Desestanco. Esta compañía lanzará su producción, de tal manera que obtendrá en 1888 la medalla de oro dada en la Exposición Universal de Barcelona de dicho año. Forman con las vecinas de Bujalcayado, en continuidad con las de Bonilla, junto con las de Alcuneza, Carabias, Gormellón, Paredes de Sigüenza, Riba de Santiuste, Rienda, 
Tordelrábano, Valdeamendras, Valdecubo y las desaparecidas de El Atance el conjunto de las salinas de la comarca de Atienza (Trailero, Arroyo y Martínez, 2003). A ellas se pueden sumar las del señorío de Molina, dentro del mismo sistema geológico salinero, como Tergaza, Armallá, Tierzo y Valdesalobre, citadas en el siglo XII en el Fuero de Molina de Aragón (Sancho, 1916), las alcarreñas de Riba de Saelices y Saelices de la Sal, recientemente recuperadas, y de Medinaceli en la vecina provincia de Soria, constituyendo el conjunto salinero de interior más importante de nuestro país.

Las salinas de Imón y Bonilla son las más importantes de este conjunto, teniendo referencias documentales desde el momento de la conquista cristiana de este territorio, en el siglo XII, aunque existan estudios de su explotación en época romana (Morére, 1991). La primera cita es de 1124 de Alfonso VII (Minguella, 1912). Alfonso VIII en 1136 dona el diezmo de las salinas de Emón y Bonella al obispo Bernardo de Siguenza, quién en 1156 destinará las rentas de las salinas a la construcción de la magnífica catedral románica del lugar. Alfonso VIII ampliará la donación en 1177 al décimo del conjunto de las rentas reales en dicho territorio, en época del obispo Arderico (González, 1960). En el primer documento de rentas reales disponible del año 1292 se cifran en 100.000 maravedíes lo generado por estas salinas, siendo el 36,3\% del conjunto de rentas de sal de la corona (Hernández, 1994). En el siglo XIV se citan las salinas de Imón y Bonilla en el Libro de la Caza de don Juan Manuel (1338-1345), señalándose a Imón en un documento de 1477 "como la mejor de todas e donde se face la sal colorada" (Ortego Rico, 2013), como identidad destacada.

Pascual Madoz, a mediados del siglo XIX, la identifica también como una de las mejores, ofreciendo datos de su producción anual: Imón entre 80.000 y 100.000 fanegas, Olmeda entre 70.000 y 80.000 fanegas, junto con otras salinas menores del grupo: Armallá entre 16.000 y 18.000 fanegas y Saelices de la Sal con 9.320 fanegas, u otras cercanas en Cuenca. Desde Imón se administraban, en ese momento, además de las salinas de La Olmeda, Saelices, Tierzo y Medinaceli, indicando que tiene un administrador, contador, 20 oficiales, medidores, guarda y aceñeros, contando con 5 norias (Madoz, 1845-50): Mayor, de Torres, de Masajos, de Enmedio y del Rincón. Edificios de planta octogonal conservados en su organización actual de los que se extraía el agua subterránea, abasteciendo a los depósitos recocederos o albercas, donde se concentraba por evaporación para ser distribuida a las eras, totalmente soladas y divididas con tablones verticales de madera, articuladas con caminos de acceso también empedrados. 

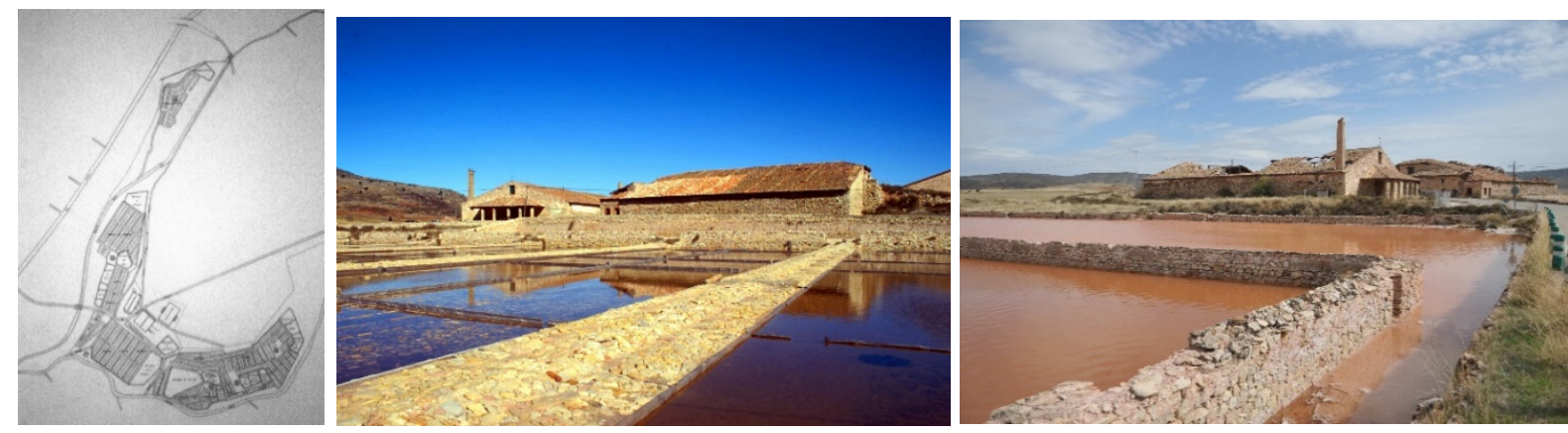

Figuras 28, 29 y 30. Salinas de Imón (Guadalara) Planta general (1983). Vistas del conjunto de almacenes (años 90 y 2019)

Fuente: Autoría José Luis García Grinda

En el centro de la explotación se sitúan tres almacenes: San Antonio, San José y San Pedro, fechados el primero en el siglo XVIII, el segundo a caballo de dicho siglo y el XIX y el tercero de la segunda mitad del siglo XIX, del que restan sólo sus muros, estando las cubiertas de los dos primeros parcialmente derrumbadas. Todo ello, a pesar de que la explotación continua en la actualidad, incluso habiendo realizado una nueva expansión hacia el norte para su extracción con maquinaria industrial, y estar declarada como BIC. Su localización junto al núcleo de Imón no exigió que tuviera edificaciones para sus empleados, pudiendo señalar las obras de terraplenado del espacio salinero, que ha necesitado de muros de contención con contrafuertes, en su borde meridional, solución común a la Olmeda.
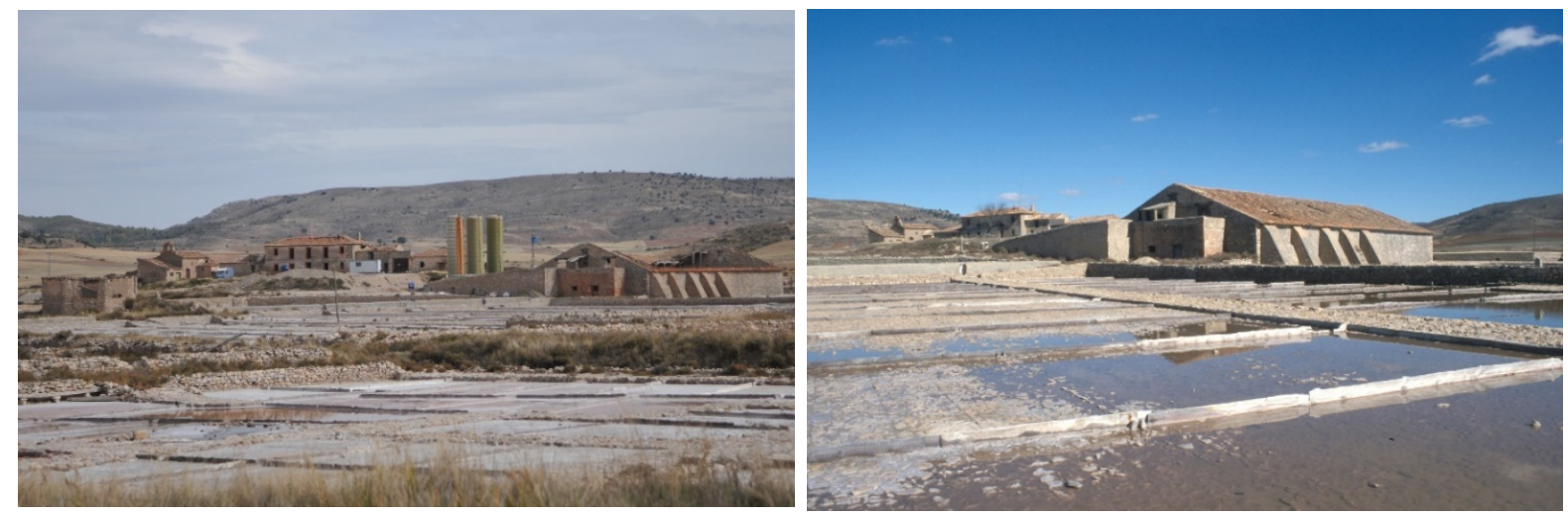

Figuras 31 y 32. Salinas de Bonilla o de La Olmeda de Jadraque (Guadalara). Vistas conjunto almacenes y casas (años 90 y 2019)

Fuente: Autoría José Luis García Grinda

Por el contrario, Las salinas de La Olmeda de Jadraque o de Bonilla se organizan en torno a un núcleo de casas de los trabajadores y administrador, al estar más alejadas del núcleo de población, junto al almacén antiguo y otro de mayor dimensión o principal, San Mateo, edificación del XVIII con su cubierta caída y dotada de contrafuertes exteriores, y una ermita que conserva parte de la fábrica medieval, con canecilos románicos que podemos fechar a finales del siglo XII o comienzos del XIII. Su organización principal está delimitada por dos cauces convergentes, arroyo de la Dehesa y río del Cubillo, convenientemente canalizados para facilitar la evacuación de las aguas, salvando su acceso principal el primero con un puente de frábica, fechado en el siglo XVIII. En este 
ámbito se disponen dos edificios de noria poligonales, uno sin cubierta y la otra ruinosa, abasteciendo a recocederos y las correspondientes eras y caminos empedrados de construcción similar a las de Imón, además de otro almacén del siglo XIX que ha perdido su cubierta junto al río del Cubillo, situándose en el extermo meridional una zona de eras abandonadas.

Hacia al sur, en plena continuidad y pegadas al río del Cubillo y su continuación en el de la Hoz, se sitúa otra zona salinera no incluída en la explotación actual, que cuentan con otras norias y partidos. Cabe señalar, que dos de las norias de Bonilla se citan en un documento de rentas de las salinas de 1477 (Ortego Rico, 2013), en las obras que se realizan en ese momento: Aceña Mayor y Aceña Nueva. A pesar del abandono parcial de esta zona, cuenta con algunas singularidades, con unos primeros partidos pegados al río del Cubillo organizados con dos edificios de norias. Uno de ellos es el único de planta circular de la comarca de Atienza, con sus recocederos, eras y caminos empedrados.

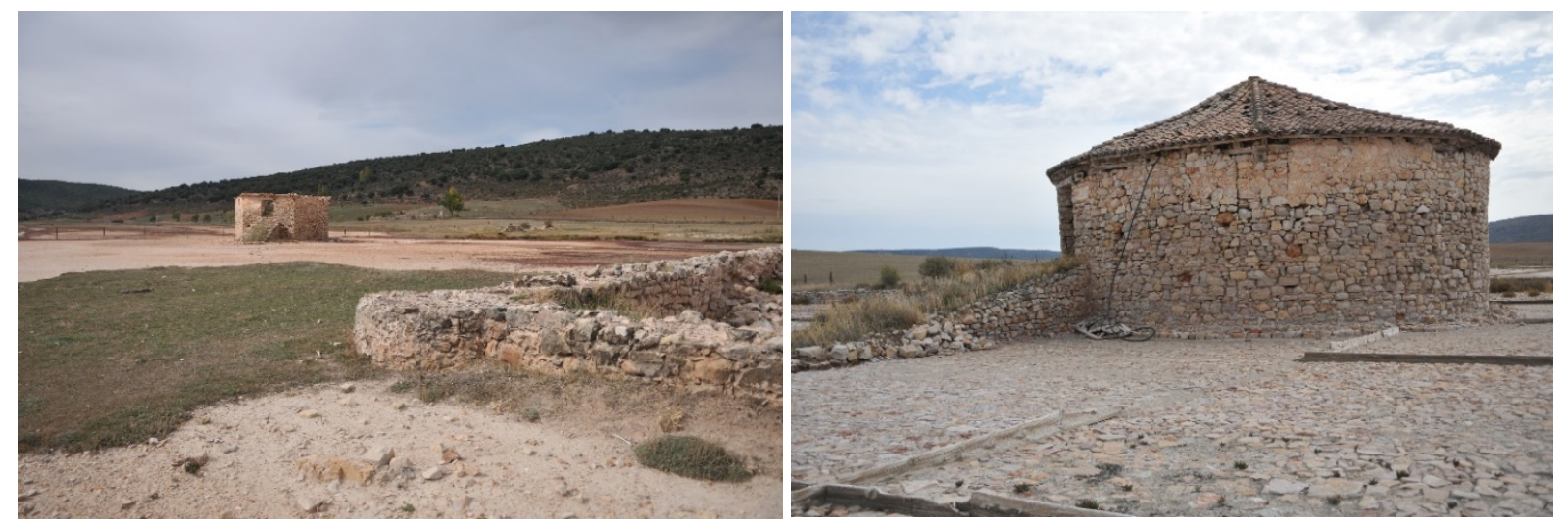

Figuras 33 y 34. Noria circular, salinas de Bonilla o de La Olmeda (Guadalajara). Recocedero con contrafuerte y antigua noria, salinas de Cirueches.

Fuente: Autoría José Luis García Grinda, 2019

Y un partido más antiguo, que recibe también la denominación de Salinas de Cirueches y que duplica en superficie a las dos zonas anteriores, más alejado hacia el suroeste, donde no quedan señales de las eras, extendido a los dos lados del río de la Dehesa continuación del río del Cubillo. Se conserva un singular edificio de noria poligonal con una potente rampa de acceso, que ha perdido su cubierta, y que abastecía a un antiguo recocedero o alberca dotado de contrafuertes en forma de torreones circulares dispuestos en sus esquinas, de clara influencia medieval, conservando restos del antiguo revestimiento de cal, junto con las ruinas de un almacén cercano y los arranques de muros de otra edificación no identificada.

Hacia el norte, a unos 200 m. y en continuidad con aquellas, se emplazan las salinas de Bujalcayado, abandonadas hace medio siglo, contando con tres norias poligonales, a medio derrumbar, los recoderos y eras empedradas de carácter similar a los de Imón, que están siendo invadidos lentamente por la vegetación, y un almacén del siglo XIX, con gran parte de su cubierta caída, dotado de la correspondiente rampa para el acceso lateral, confirmando el lamentable estado de abandono que puede extender al conjunto del resto de las salinas de Atienza 
y ámbitos conexos y sus elementos arquitectónicos, con la citada excepción de Saelices de la Sal.

Unas salinas que se han mantenido en actividad hasta nuestros días, aunque con serias dificultades son las de Belinchón (Cuenca). Nuestro contacto con ellas se produjo al realizar una serie de estudios de la arquitectura popular de distintas comarcas conquenses, en concreto la de Mancha Alta donde se insertan, junto con otros espacios salineros abandonados, como las de Monteagudo de las Salinas, reflejados en distintas publicaciones (García Grinda, 2005 y 2006). Aunque existen indicios de explotación en época romana (Osuna y Suay, 1975), además de estar además vinculadas a calzadas importantes tanto Belinchón como Monteagudo (Palomero, 1987), tuvieron explotación segura en época árabe, al estar citadas en los primeros momentos de la conquista cristiana. La primera vinculada a Belchúm, nombre árabe de Belinchón, donando Alfonso VII en 1146 dichas salinas al obispado de Toledo junto con la mitad de sus términos, mientras Monteagudo es citado en la donación del castillo árabe del cual dependía, realizada por Alfonso VIII en 1187 (González, 1975). Las de Belinchón son disputadas en el siglo XIII entre el obispado de Toledo y la Orden de Santiago, obteniendo está ultima su control mediante las concesiones que realiza Fernando III en 1246 y 1249, estimándose la producción según las rentas obtenidas en 48.000 fanegas (González, 1975), siendo en estos momentos una de las más importantes del reino, junto con las de Atienza, en concreto Imón y Bonilla, y las de Poza y Añana.

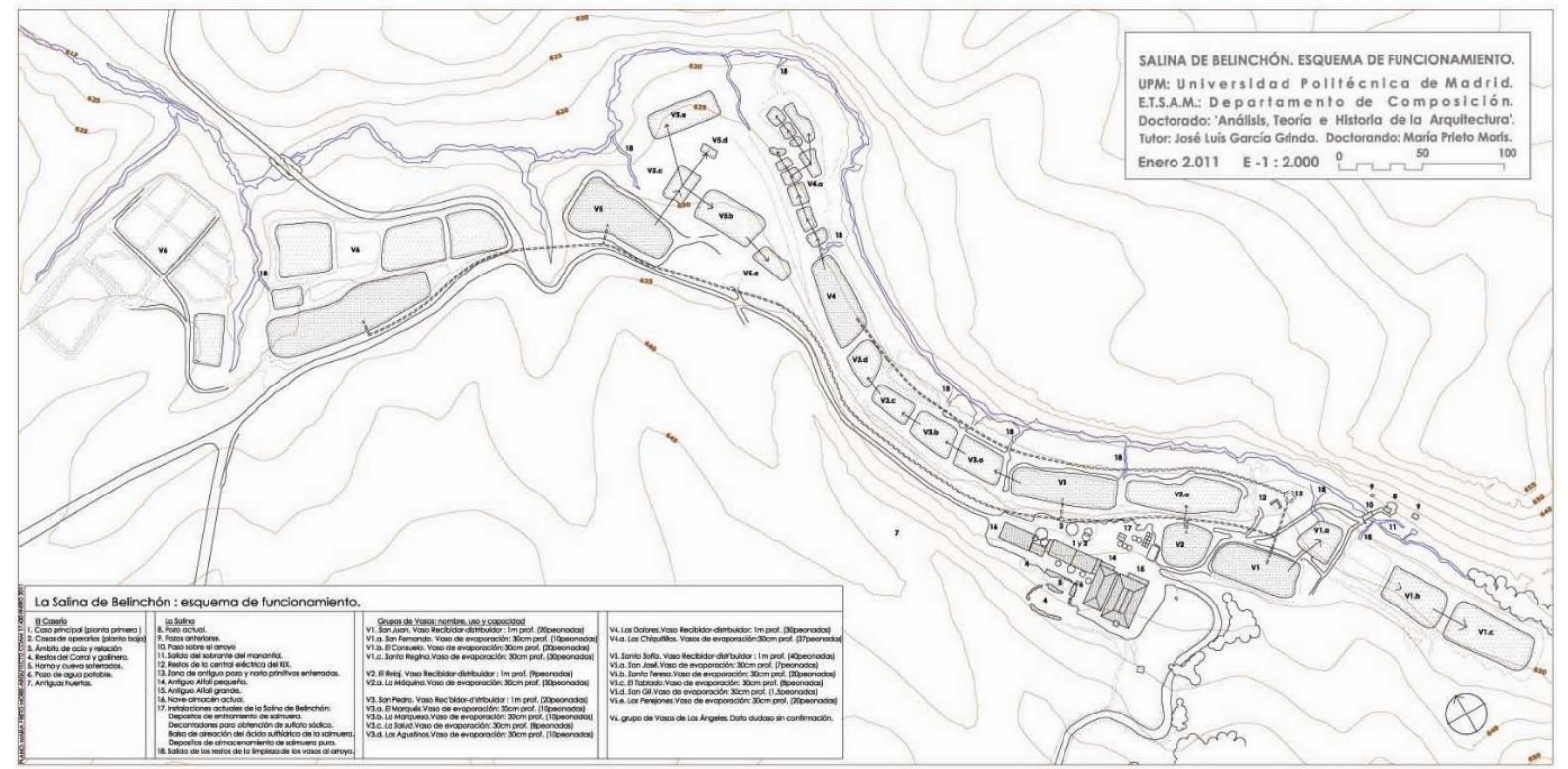

Figura 35. Salinas de Belinchón. Planta general (2011)

Fuente: Autoría María Prieto Moris (2013)

Madoz nos relata que las Belinchón abastecen, en el siglo XIX, a Madrid y poblaciones de su entorno, indicando que, junto al administrador y contador, tienen de diez a doce empleados, extrayendo el agua por una noria, contando con escelentes almacenes y casas. Ofrece datos de su producción anual, que claramente ha ido progresivamente en decadencia desde época medieval: Belinchón con 12.000 fanegas y Monteagudo de las Salinas con 6.700 fanegas (Madoz, 1845-50). Serán adjudicadas en 1873 al Marqués de Remisa, cuñado de la Reina Madre Ma Cristina, después de haber sido cerradas en 1866 al haberse 
agotado el pozo antiguo. Instalará un balneario que usará con frecuencia la reina Isabel II (Prieto, 2013), junto a las casas del lugar, destacando la del administrador con su escudo real, en paralelo a los baños de ola que la corona popularizará con su estancia veraniega en sus palacios de Santander y San Sebastián aprovechando las propiedades del agua salina. La edificación del balneario será destruída en la Guerra Civil, conservándose las bañeras originales talladas en piedra.

Las salinas actualmente conservan además de las casas citadas y junto a ellas, dos almacenes de planta rectangular y fechados en el siglo XVIII. El pequeño, de mayor antigüedad, está dotado con una línea central de pilares de madera, mientras el mayor tiene dos líneas simétricas de postes, sustentando la estructura de la cubierta, reforzando en ambos casos, con contrafuertes, las esquinas. Ha desparecido la citada noria sustituida por una bomba que extrae agua del pozo, así como las canalizaciones de madera, incluso elevadas, que abastecían los recocederos y la ermita de San Juan Bautista, sita en su jurisdicción. Las eras, al contrario que las Monteagudo, no están soladas de modo continuo, estando conformadas por tierra y piedra mezcladas, reforzadas lateralmente con piezas de piedra y madera, adaptadas en paralelo a la margen meridional de la vaguada y arroyo de la Vega o Salado.

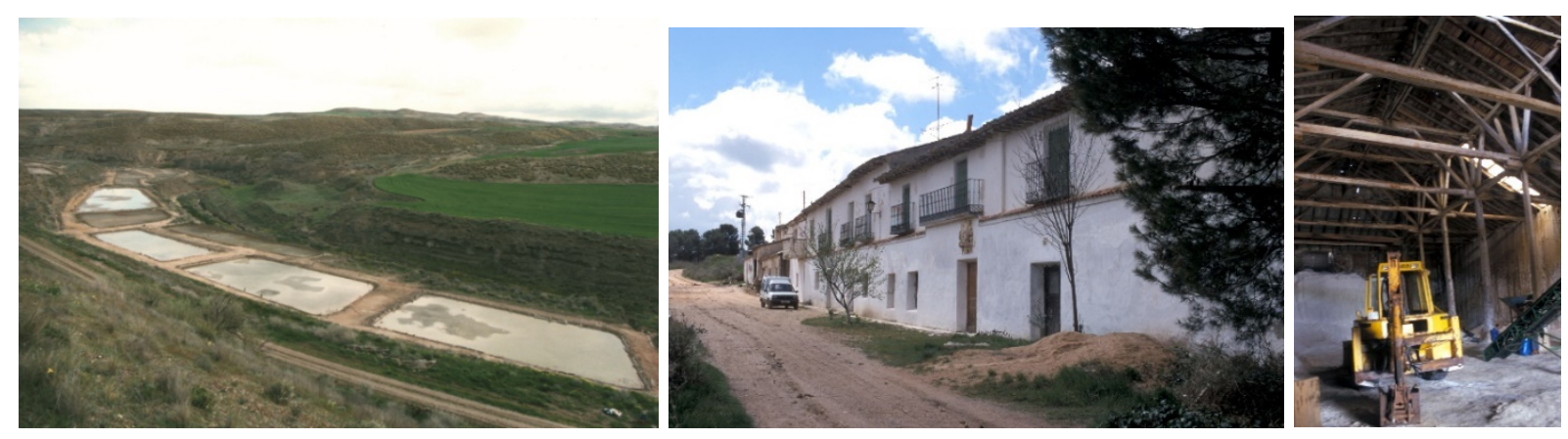

Figuras 36, 37 y 38. Salinas de Belinchón: Eras, interior del almacén mayor y casas del administrador y empleados.

Fuente: Autoría José Luis García Grinda, 2002

\subsection{Almacenes y alfolís}

Uno de los elementos arquitectónicos más destacados son los almacenes y alfolíes que permitieron guardar y proteger la sal extraída, emplazados tanto en los espacios de extracción, salinas y minas de sal, como en las poblaciones para permitir, en este caso, su control y venta. Hay que recordar, en tal sentido, el importante papel que la sal tiene en la conservación y elaboración de alimentos, como hemos visto con el pescado desde la antigüedad, así como en el importante papel en la ganadería, permitiendo que el ganado no se deshitrate en época calurosa, dándole la sal gorda, en forma de bloques o "granzuela", para ser lamida. Ello queda reflejado en el privilegio XXX de los Cuadernos de Leyes de la Mesta, donde se concede medio celemín, unos seis kilos, de forma gratuita a cada mesteño que lo solicite, siendo muy significativo que vías pecuarias importantes discurran cercanas o vecinas a las salinas interiores más importantes, como las citadas en el texto de Poza, Imón o La Olmeda, como ocurría con las calzadas romanas (Menéndez Pidal, 1951). 
Conocemos como la Cabaña Real de Carreteros, la hermandad gremial más importante del Reino de Castilla después de la Mesta, apoyada en distintas legislaciones desde las Leyes de Toro y consolidada y reconocida, en 1497, por los privilegios dados por los Reyes Católicos (Tudela, 1963), era habitualmente la encargada del transporte desde los almacenes salineros a los alfolís sitos en las distintas poblaciones y controlados por los principales concejos. Se ha estudiado con cierto detalle el transporte que realizaba la Junta y Hermandad de BurgosSoria, la más importante del reino, particularmente el de la sal, a lo largo de los siglos XVI al XIX (Gil Abad, 1983).

Se conservan un buen número de almacenes de salinas, de los cuales se han dado referencia en las de interior reseñadas, una mayoría de ellos edificados en el siglo XVIII y primer tercio del XIX, como el de Tierzo, fechado en 1770 en el reinado de Carlos III en su portada, y con contrafuertes circulares al exterior. De ellos se puede destacar el de San Antonio de Imón, fechado en el siglo XVIII, con una interesante solución de doble galería superior apoyada en dos hileras de pies derechos y viguería de madera, dejando un espacio central y dos laterales libres de su planta rectangular, y conectada con una rampa que permitía descargar desde su altura la sal con el transporte de caballerías, a fin de llenar en su altura el almacén. Similar solución la encontramos también en dichas salinas en el almacén de San José, de mayor anchura y algo más tardío en su construcción. En otras salinas podemos indicar otras edificaciones destinadas también a alfolíes con restos anteriores, como en Naval (Huesca), con pilastras circulares del siglo XVI, o en Gerri de la Sal (Lérida), con una edificación que ha tenido distintas fases de construcción desde finales del XV al XIX, tanto destinada a la administración, como a almacén de sal, destacando sus espacios abovedados destinados al último fin. Otras soluciones tradicionales emplean cerramientos de tabla, como encontramos en un antiguo almacén en Añana, o sirven estos de recubrimiento interior para proteger del ataque de la sal a las fábricas de los muros, como hallamos en el almacén mayor de Belinchón.
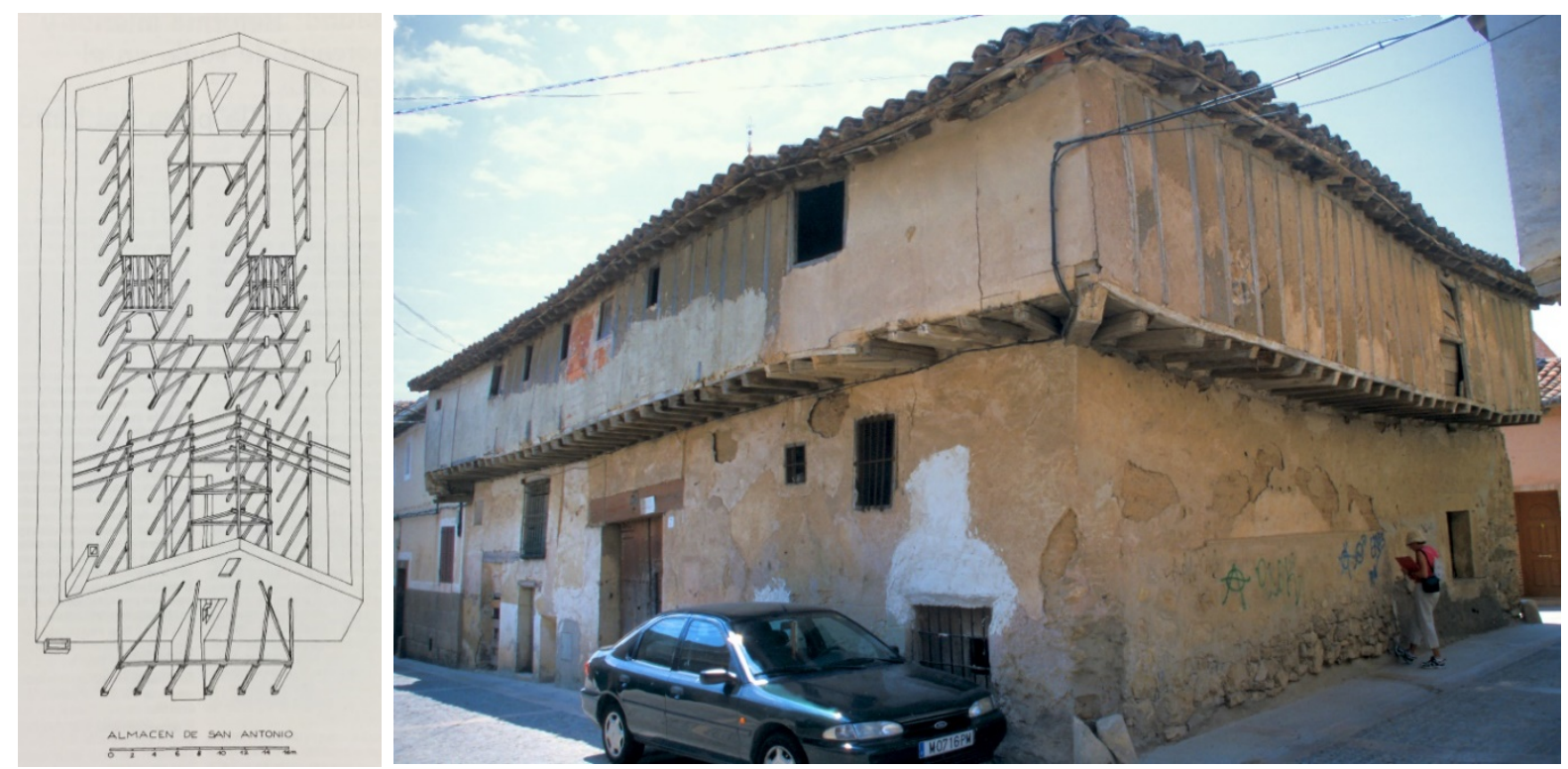

Figuras 39 y 40. Perspectiva del almacén de San Antonio, salinas de Imón (1983). Alfolí de Torrelaguna (Madrid), año 2005.

Fuente: Autoría José Luis García Grinda 
Los alfolís o depósitos que adminstraban y vendían la sal, situados en las principales poblaciones podían ser sustituídos en sus funciones por algunos pósitos o cillas. Se reguló desde época medieval los lugares que podían tener estos edificios y servicios, controlando su venta y fiscalidad. Por ejemplo, en las poblaciones vinculadas a las salinas de la comarca de Atienza, donde se prohibía, en 1447, por Enrique II, la construcción de pósitos en lugares que no fueran Ayllón, Torrelaguna, Junquera, San Esteban de Gormaz y Soria (Ortego, 2013). Se conserva el alfolí de Torrelaguna (Madrid), aunque ha tenido una rehabilitación reciente que ha alterado su anterior aspecto. La edificación de tradición medieval, cuenta con un cuerpo superior volado cerrado con entramado de madera y adobe, conservando en su interior un espacio subterráneo abovedado destinado al almacén de la sal, aunque su uso principal anterior a la rehabilitación fue de lagar y vivienda. Ejemplares espectaculares como el de L'Escala (Gerona), lugar pesquero vinculado a conocidas salazones tradicionales, fechado en el siglo XVIII, con amplio patio lateral y trasero para carga y descarga, espacios abovedados en su planta baja destinados como almacén y dos plantas superiores para la administración y viviendas de empleados y administrador.

Y desde luego se conservan documentos de proyectos y obras de alfolís del siglo XVIII, como el principal de Zaragoza, con su planta cuadrada. También podemos encontrar edificios históricos singulares, como el Palacio de la Salina de Salamanca, donde Rodrigo Gil de Hontañón se encargará de rematar su cuerpo principal en 1538 (Álvarez, 1984), dotado de una espectacular arcada, dando acceso a un patio que articula su planta en $U$. En el sótano se conserva un espacio abovedado como almacén de sal conectado directamente al patio mediante una escalera. Esta casa palacial sirvió como alfolí de la ciudad de Salamanca hasta 1871, al tener su propietario Juan Alonso de Fonseca, segundo hijo de don Rodrigo de Messía Carrillo y doña Mayor de Fonseca y Toledo quienes ordenaron construir el edificio en el primer tercio del siglo XVI, el monopolio de la venta de la sal; y como tal se entiende la fachada que invita a entrar desde el espacio público de la calle.
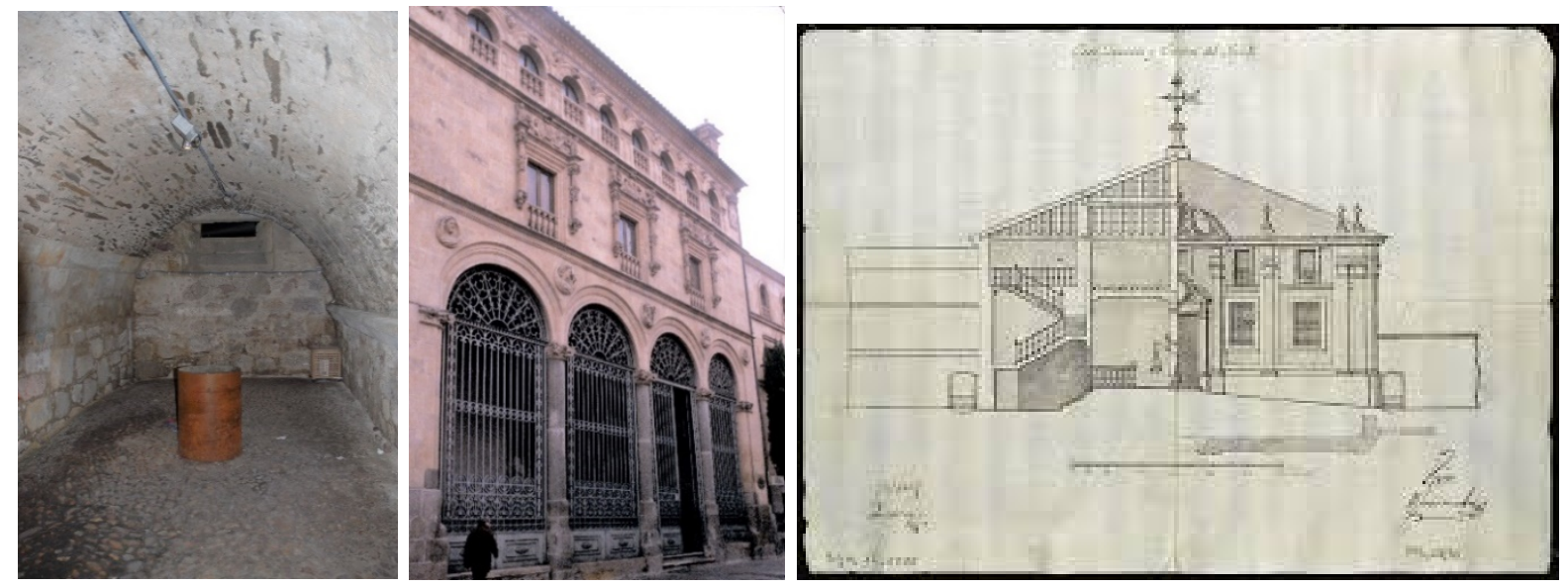

Figuras 41, 42 y 43. Palacio de la Salina, fachada y sótano para alfolí. Alfolí principal de Zaragoza, sección y alzado (1760), Velasco Yarza.

Fuente: Autoría fotos José Luis García Grinda. Plano AGS, Dirección General de Rentas, Primera Remesa, leg. 02285 


\section{BIBLIOGRAFÍA}

Abásolo, J.A., Albertos, M. L. y Elorza, J.C. (1975) Los Monumentos funerarios de época romana, en forma de casa, de la región de Poza de la Sal (Bureba, Burgos). Burgos: Diputación Provincial.

Álvarez Villar, J. (1987) El Palacio de la Salina de Salamanca. Salamanca: Diputación Provincial.

Carta de Cracovia. Principios para la conservación del Patrimonio Construido (2000).

Don Juan Manuel (1337-1348) Libro de la Caza. Ed. Blecua, J.M. (1981) Madrid.

Estrabón (7 aC.) Geographia. (L. III) Ed. García Bellido, A. España y los españoles hace dos mil años (1945) Madrid: Espasa Calpe

García Bellido, A. (1953) La Península Ibérica en los comienzos de su historia. Madrid: CSIC. Ed. Fac. (1985). Madrid: Ediciones Itsmo.

García Grinda, J.L., García Alba, A., Jaraba Melgarejo, F., Cespedosa, R., y Martín Garrido, C. (1977-78) Reseña del Patrimonio Arquitectónico y Urbanístico de la Provincia de Burgos, Colegio Oficial de Arquitectos de Madrid. Delegación de Burgos. Documento original con 15 tomos.

García Grinda, J.I., García Alba, A., Jaraba Melgarejo, F., Cespedosa, R. y Martín Garrido, C. (1979-80) Inventario del Patrimonio Arquitectónico de la Provincia de Burgo. Dirección General de Bellas Artes, Ministerio de Cultura. Documento original con 3.705 fichas.

García Grinda, J.L. (1982) Comentarios sobre la memoria de la convocatoria del concurso para la redacción de los Inventarios del Patrimonio Arquitectónico. Revista Q. Consejo Superior de Arquitectos. No 52 (pp. 14-24).

García Grinda, J.L. (1983) Las salinas de Imón en Guadalajara, parte de un conjunto salinero. Revista Q. Consejo Superior de Arquitectos. No64 (pp. 28-35).

García Grinda, J.L. (1983, 1984. 2Ed.) Burgos Edificado. Madrid: COAM.

García Grinda, J.L. (2005) Cuaderno de arquitectura de la Comarca natural de la Mancha Alta Conquense 2. La Arquitectura auxiliar, complementaria y del común. Cuenca: ADESIMAN, PROGRAMA PRODER-2.

García Grinda, J.L. (2006) Cuaderno de arquitectura de la Comarca natural de la Serranía Media 2. La Arquitectura auxiliar, complementaria y del común. Cuenca: ADESIMAN, PROGRAMA PRODER-2.

Gil Abad, P. (1983) Junta y Hermandad de la Cabaña Real de Carreteros BurgosSoria. Burgos: Diputación Provincial. 
González González, J. (1960) El Reino de Castilla en la época de Alfonso VIII. Madrid: CSIC.

González González, J. (1975) La repoblación de Castilla la Nueva. Madrid: Universidad Complutense.

Hemptel, P.M. (1967) Der Diapir von Poza de La Sal (Nordspanien). En Diapirtectoni kund stratigraphie in Vorland des Spanischen West pyrenäen, Belth. Geol. Jb. 66. Hannover (pp. 66-126).

Hernández, F.J. (1994) Las rentas del rey: Sociedad y fisco en el reino castellano del siglo XIII. Madrid: F. Ramón Areces.

Iniesta Sanmartín, A. y Martínez alcalde, M. (2005) Factoría romana de salazones (Puerto de Mazarrón, Murcia) Revista de Museología. No 33-34 (pp.7078).

Madoz, P. (1845-1850) Diccionario Geográfico-estadístico-histórico de España y sus posesiones de Ultramar. Ed. Fac. (1987) Valladolid: Ed. Ámbito y Junta de Comunidades de Castilla-La Mancha.

Marín, C. y Luengo, A. (1994) El jardín de la sal. Santa Cruz de Tenerife: Consejo Científico para el Desarrollo de las Isla y Gobierno Canario.

Menéndez Pidal, G. (1951) Los Caminos en la Historia de España. Madrid: Instituto de Cultura Hispánica.

Minguella Arnedo, T. (1912) Historia de la diócesis de Siguenza y sus obispos. Madrid: Imp. Revista Archivos, Bibliotecas y Museos.

Morére Molinero, N. (1991) L'explotation romaine du sal dans le región de Siguenza. R. Gerión (pp. 223-236).

Morris, W. (1884) Prospects of Architecture in Civilitation. On Art and Socialism, Londres (p. 141).

Ortego Rico, P. (2013) Las salinas de Atienza, Medinaceli y Molina de Aragón en la Baja Edad Media. R. Historia, Instituciones, Documentos. No 40 (p. 212). Archivo G. Simancas, EMR, leg. 28, f. 161.

Osuna Ruiz, M. y Suay Martínez, F. (1974) Yacimientos romanos de la provincia de Cuenca. Revista Cuenca. No 6 (pp. 25-59)

Palomero Plaza, J. (1987) Las vías romanas en la provincia de Cuenca. Cuenca: Diputación Provincial.

Ponsich, M y Tarradell, M. (1965) Garum et industries antiques de salaison dans la Mediterranée Occidentale. Paris: Presses Universitaires de France.

Ponsich, M. (1988) Aceite de oliva y salazones de pescado. Factores geoeconómicos de Bética y Tingitania. Madrid: Universidad Complutense. 
Prieto Moris, Ma (2013) Las salinas de interior de la Cuenca del Tajo: las salinas de Belinchón. Trabajo original de Prácticas de Investigación. Doctorado Composición Arquitectónica. Escuela Técnica Superior de Arquitectura. Universidad Politécnica de Madrid. Director: José Luis García Grinda

Sáiz Alonso, E. (1989) Las salinas de Poza de la Sal. Burgos: Diputación Provincial.

Sancho Izquierdo, M. (1916) El fuero de Molina de Aragón. Madrid: Victorio Súarez.

Trailero Sanz, A., Arroyo San José, J. y Martínez Señor, V. (2003) Las Salinas de la Comarca de Atienza. Guadalajara: Aache Ediciones.

Tovar, A. y Blázquez J.A. (1975) Historia de la España Romana. Madrid: Alianza Editorial.

Tudela, J. (1963) La Cabaña Real de Carreteros. Separata del Homenaje a Ramón Carande. Madrid: Sociedad de Estudios y Publicaciones. 